\title{
Protection of steel with a superhydrophobic coating against atmospheric corrosion in conditions of livestock buildings
}

\author{
L.E. Tsygankova, ${ }^{1,2}{ }^{(1) *}$ A.A. Uryadnikov, ${ }^{1,2}$ A.V. Dorokhov, ${ }^{1,2}$ \\ L.G. Knyazeva, ${ }^{1,2}$ N.V. Shel ${ }^{3}$ and L.D. Rodionova ${ }^{1}$ \\ ${ }^{1}$ Derzhavin State University, ul. Internatsyonalnaya, 33, 392000 Tambov, Russian \\ Federation \\ ${ }^{2}$ All-Russian Scientific Research Institute of Use of Machinery and Oil Products, Novo- \\ Rubezhnyi per., 28, 392022 Tambov, Russian Federation \\ ${ }^{3}$ Tambov State Technical University, ul. Sovetskaya, 106, 392000 Tambov, Russian \\ Federation \\ *E-mail: vits21@mail.ru
}

\begin{abstract}
Superhydrophobic coatings were obtained by texturing the steel surface with a nanosecond IR laser followed by treatment with ultraviolet radiation in the presence of ozone plasma. Further,

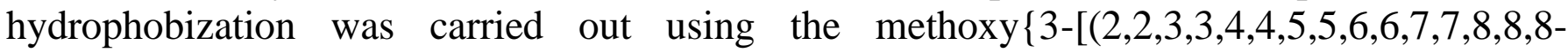
pentadecafluorooctyl)oxy]propyl $\}$ silane hydrophobizing agent. The contact angle on the obtained samples was $172.6 \pm 1.2^{\circ}$. Corrosion tests of St3 steel samples without and with a superhydrophobic coating were carried out in an atmosphere with $100 \%$ humidity and the presence of corrosion stimulants $\mathrm{CO}_{2}, \mathrm{H}_{2} \mathrm{~S}$ and $\mathrm{NH}_{3}$ in pairs and simultaneously all three in the maximum permissible concentrations for livestock buildings. After 100 days of exposure of the samples in the atmospheres under study the contact angle decreased to $167-162^{\circ}$. Such a slight decrease in the contact angle indicates the high protective properties of the superhydrophobic coating. There were no corrosion losses in samples with a superhydrophobic coating; on the contrary, an insignificant weight gain was observed. Under conditions of $100 \%$ humidity, a moisture film forms on the surface of the samples, in which gases present in the atmosphere dissolve and hydrolyze. In this case, solutions of $\mathrm{H}_{2} \mathrm{~S}, \mathrm{H}_{2} \mathrm{CO}_{3}, \mathrm{NH}_{4} \mathrm{OH}$ are formed. The presence of these substances on the surface contributes to the formation of insoluble corrosion products in the pores of the coating, which leads to an insignificant weight gain of the samples. At the same time, steel samples without a protective coating underwent intense corrosion.
\end{abstract}

Keywords: atmospheric corrosion, steel, protection, superhydrophobic coating, corrosion stimulants, contact angle.

Received: November 12, 2021. Published: November 24, 2021

doi: $\underline{10.17675 / 2305-6894-2021-10-4-16}$

\section{Introduction}

Atmospheric corrosion of metals and alloys often occurs in the presence of aggressive components in the atmospheric air that are corrosion stimulators (CS) (in addition to 
oxygen), which can be, in particular, $\mathrm{SO}_{2}, \mathrm{H}_{2} \mathrm{~S}, \mathrm{CO}_{2}$ and $\mathrm{NH}_{3}$. They are present in the atmosphere due to, for example, technological processes for the processing of metal sulfides $\left(\mathrm{SO}_{2}\right.$ and $\left.\mathrm{H}_{2} \mathrm{~S}\right)$, the operation of livestock complexes $\left(\mathrm{NH}_{3}, \mathrm{CO}_{2}\right.$ and $\left.\mathrm{H}_{2} \mathrm{~S}\right)$. Moreover, according to the standards for livestock buildings, the permissible concentrations of hydrogen sulfide and ammonia can reach $10 \mathrm{mg} / \mathrm{m}^{3}$ and $20 \mathrm{mg} / \mathrm{m}^{3}$, respectively (the concentration of $\mathrm{CO}_{2}$ is not standardized). This leads to a highly corrosive air environment, especially if the relative humidity $(\mathrm{H})$ is close to $100 \%$.

Over the past two decades, abroad and in Russia, an intensive study of hydrophobization and superhydrophobization of surfaces has been carried out to protect metals against corrosion in corrosive environments. The effect of coatings increasing the contact angle of wetting with water to $\geq 150^{\circ}$ is considered. Much attention is paid to the application of protective films of superhydrophobizing agents, which make it possible to increase the contact angle to $165-171^{\circ}$. The research results are summarized in a number of reviews [1-4]. To form superhydrophobic coatings on metals, it is necessary to create a multimodal surface roughness followed by the application of hydrophobic materials with low surface energy. Various methods are used to create surface roughness, such as chemical etching [5], chemical vapor deposition [6], nanosecond laser surface treatment [7], etc. Fluoroxysilanes, fluorocarbons, organic acids and amines with a long hydrocarbon chain, etc. are used as hydrophobic materials.

Usually, the protective effectiveness of such coatings is studied in a neutral chloride solution, a salt fog chamber, or under conditions of $100 \%$ humidity $[8,9]$.

Earlier, we carried out gravimetric corrosion tests of St3 carbon steel samples with a superhydrophobic coating based on methoxy\{3-[(2,2,3,3,4,4,5,5,6,6,7,7,8,8,8-pentadecafluorooctyl)oxy]propyl $\}$ silane for 112 days under conditions of $100 \%$ humidity [10]. Corrosion losses were absent, the contact wetting angle after the experiment had the same value as before the start of the experiment $\left(172^{\circ}\right)$.

The aim of this work is to evaluate the protective effectiveness of superhydrophobic coatings on carbon steel in the presence of high concentrations of aggressive components $\mathrm{NH}_{3}, \mathrm{CO}_{2}$ and $\mathrm{H}_{2} \mathrm{~S}$ in the air under conditions of $100 \%$ humidity.

\section{Experimental}

The studies were carried out on St 3 carbon steel with a chemical composition, mass \%: $\mathrm{C}-0.20 ; \mathrm{Mn}-0.50 ; \mathrm{Si}-0.15 ; \mathrm{P}-0.04 ; \mathrm{S}-0.05 ; \mathrm{Cr}-0.31 ; \mathrm{Ni}-0.23 ; \mathrm{Cu}-0.21 ; \mathrm{Fe}$ rest.

Superhydrophobic coatings based on the methoxy- $\{3-[(2,2,3,3,4,4,5,5,6,6,7,7,8,8,8$ pentadecafluorooctyl)oxy]propyl $\}$ silane hydrophobizator were applied to the surface of steel electrodes in the Laboratory of Surface forces at the Institute of Physical Chemistry and Electrochemistry, Russian Academy of Sciences according to the method described in [10]. The wetting angle on the obtained superhydrophobic samples was $172.6 \pm 1.2^{\circ}$, the roll-off angle was $2.5 \pm 1^{\circ}$. 
Gravimetric corrosion tests of steel samples with and without a superhydrophobic coating were carried out in sealed desiccators, in which the specified concentrations of the corrosion stimulants under study were created at $100 \%$ humidity according to [11].

Before and after exposure of the coated samples under the specified conditions, the wetting angles were measured at 3-5 different points on the surface for the distilled water droplets with volume $2-3 \mu \mathrm{L}$ using a tensiometer (Easy Drop, KRUSS, Germany). Moreover, the samples were preliminarily washed with bidistillate, blotted with filter paper and kept in air for an hour before weighing and measuring the contact angle. A scanning electron microscope (JSM 6390, JEOL, Japan) was used to assess the condition of the coating surface.

\section{Results and Discussion}

The structure of the initial superhydrophobic surface of the steel sample is shown in Figure 1. Multilevel roughness is clearly visible.

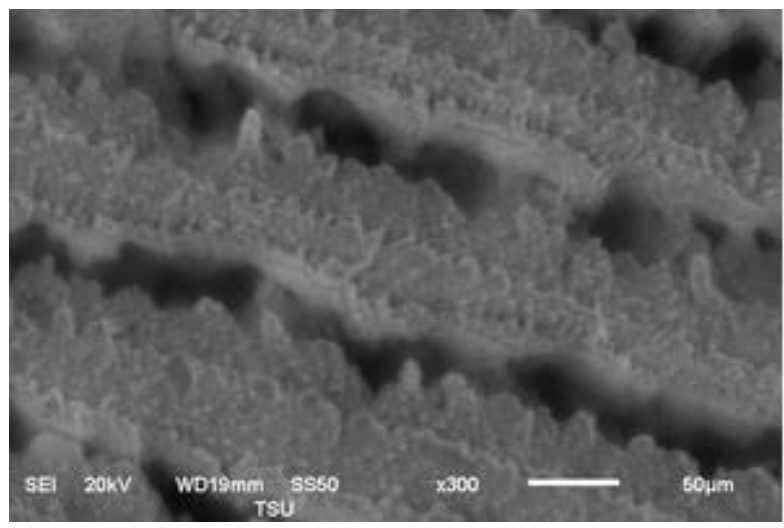

Figure 1. SEM images of the initial surface of steel with superhydrophobic coating.

Corrosion tests of steel samples with and without a protective coating were carried out in an atmosphere with $100 \%$ humidity in the presence of two stimulants $\left(\mathrm{CO}_{2}\right.$ and $\mathrm{H}_{2} \mathrm{~S} ; \mathrm{NH}_{3}$ and $\mathrm{H}_{2} \mathrm{~S}$ and $\mathrm{CO}_{2}$ and $\mathrm{NH}_{3}$ ) and simultaneously all three in maximum permissible concentrations for livestock buildings. Table 1 shows the corrosion rates of unprotected steel samples under the specified conditions, and in Figure 2 the appearance of the samples after testing is shown.

Table 1. Corrosion rates of St3 steel without coating in the presence of $\mathrm{CSs} \mathrm{NH}_{3}, \mathrm{H}_{2} \mathrm{~S}$ and $\mathrm{CO}_{2}$ in concentrations equal to $20 \mathrm{mg} / \mathrm{m}^{3}, 10 \mathrm{mg} / \mathrm{m}^{3}$ and $0.2 \mathrm{vol} . \%$, respectively, at $100 \%$ relative humidity.

\begin{tabular}{ccccc}
\hline Conditions & $\begin{array}{c}\mathrm{CO}_{2}+\mathbf{H}_{2} \mathrm{~S} \\
\boldsymbol{\tau}=106 \text { days }\end{array}$ & $\begin{array}{c}\mathrm{CO}_{2}+\mathbf{N H}_{3} \\
\boldsymbol{\tau}=106 \text { days }\end{array}$ & $\begin{array}{c}\mathbf{N H}_{\mathbf{3}}+\mathrm{H}_{2} \mathrm{~S} \\
\boldsymbol{\tau}=97 \text { days }\end{array}$ & $\begin{array}{c}\mathrm{CO}_{2}+\mathrm{H}_{2} \mathbf{S}+\mathrm{NH}_{3} \\
\boldsymbol{\tau}=\mathbf{9 7} \text { days }\end{array}$ \\
\hline$K, \mathrm{~g} /\left(\mathrm{m}^{2} \mathrm{~h}\right)$ & 0.0233 & 0.0396 & 0.0049 & 0.0081 \\
\hline
\end{tabular}


As can be seen from Figure 2, steel samples in the presence of corrosion stimulants under conditions of $100 \%$ humidity undergo significant corrosion.

The degradation of the superhydrophobic coating during exposure to an aggressive environment can be judged by the change in the wetting angle value, since it is determined by the structure and state of the surface layer [8]. Figure 3 shows the changes in time of the values of the wetting angles under different conditions of the experiment.

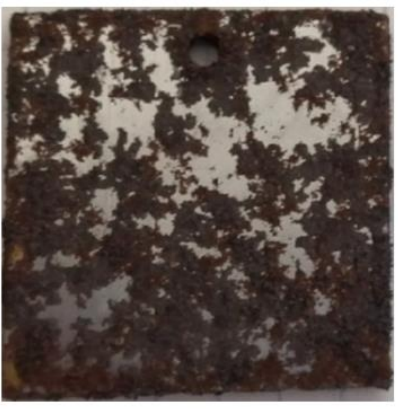

1

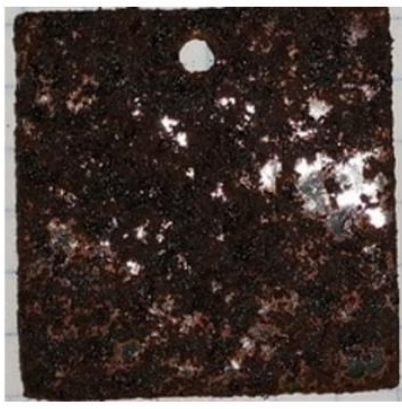

2

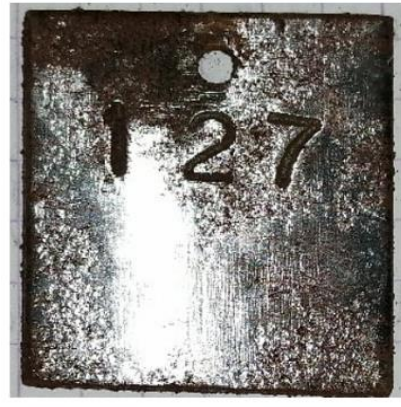

3

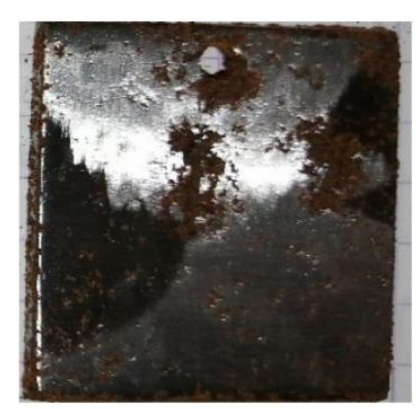

4

Figure 2. Appearance of St3 steel samples after exposure to $100 \%$ humidity in the presence of $\mathrm{CO}_{2}+\mathrm{H}_{2} \mathrm{~S}(1), \mathrm{CO}_{2}+\mathrm{NH}_{3}$ (2), $\mathrm{NH}_{3}+\mathrm{H}_{2} \mathrm{~S}$ (3), $\mathrm{CO}_{2}+\mathrm{H}_{2} \mathrm{~S}+\mathrm{NH}_{3}$ (4). Duration of tests, days: 1 and $2-106 ; 3$ and $4-97$.

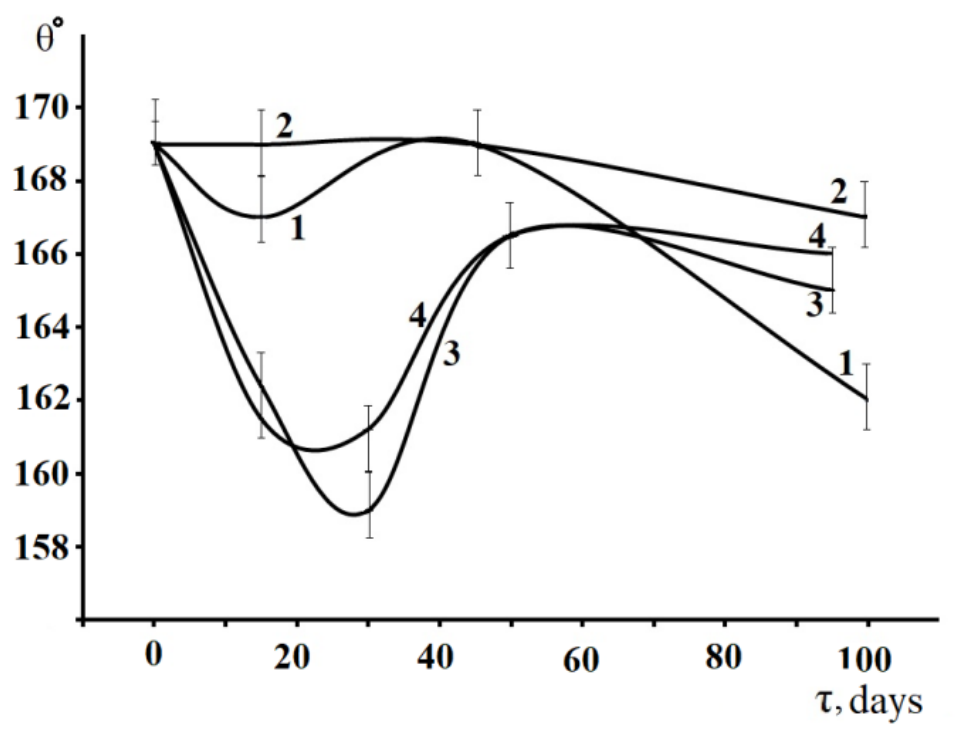

Figure 3. Change in time of the contact angle of wetting of a superhydrophobic coating on a steel electrode after holding it under conditions of $100 \%$ humidity in the presence of $\mathrm{CO}_{2}+\mathrm{H}_{2} \mathrm{~S}$ (1), $\mathrm{CO}_{2}+\mathrm{NH}_{3}$ (2), $\mathrm{NH}_{3}+\mathrm{H}_{2} \mathrm{~S}(3), \mathrm{CO}_{2}+\mathrm{H}_{2} \mathrm{~S}+\mathrm{NH}_{3}$ (4). Test duration, days: 1 and $2-106 ; 3$ and $4-97$.

In the first 10-30 days, a decrease in the contact angle value is observed in atmospheres containing hydrogen sulfide. The smallest decrease is typical for the atmosphere with $\mathrm{CO}_{2}+\mathrm{H}_{2} \mathrm{~S}$ - about $3^{\circ}$, the largest - about $10^{\circ}$ - in atmospheres with $\mathrm{NH}_{3}+\mathrm{H}_{2} \mathrm{~S}$ and 
$\mathrm{CO}_{2}+\mathrm{H}_{2} \mathrm{~S}+\mathrm{NH}_{3}$. But by 50 days, the contact angle increases to $169^{\circ}$ in the first case and $167^{\circ}$ in the last two, reaching within 100 days the values of $162^{\circ}$ in the atmosphere with $\mathrm{CO}_{2}+\mathrm{H}_{2} \mathrm{~S}$ and $165-166^{\circ}$ in atmospheres with $\mathrm{NH}_{3}+\mathrm{H}_{2} \mathrm{~S}$ and $\mathrm{CO}_{2}+\mathrm{H}_{2} \mathrm{~S}+\mathrm{NH}_{3}$. Images of water droplets on the surface of the samples at different time intervals are shown in Figure 4-7.

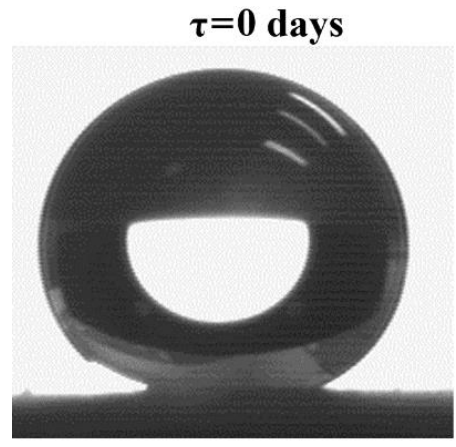

$\Theta=168^{\circ}$

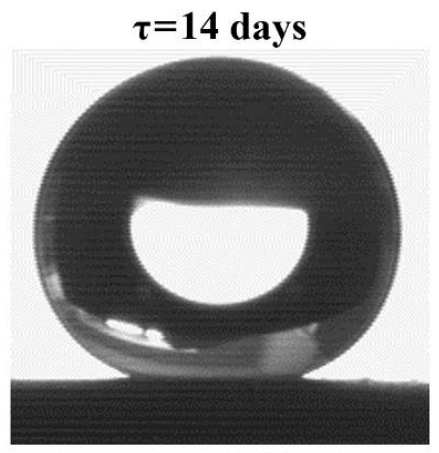

$\Theta=167^{\circ}$

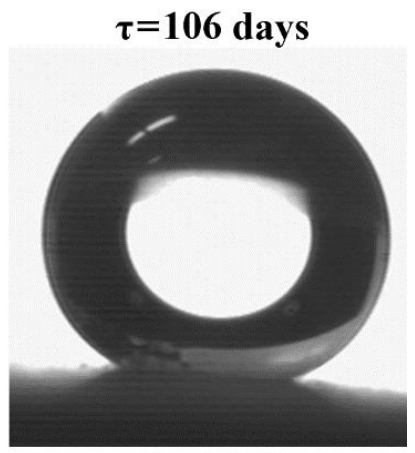

$\Theta=164^{\circ}$

Figure 4. Images of water droplets on the surface of a superhydrophobic coating at different times of exposure of the samples in an atmosphere with $\mathrm{CO}_{2}$ and $\mathrm{H}_{2} \mathrm{~S}$ under $100 \%$ humidity conditions.

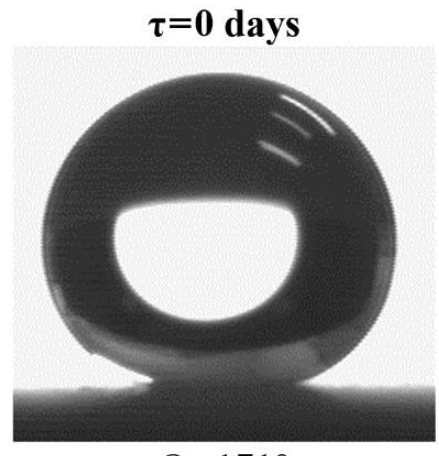

$\Theta=171^{\circ}$

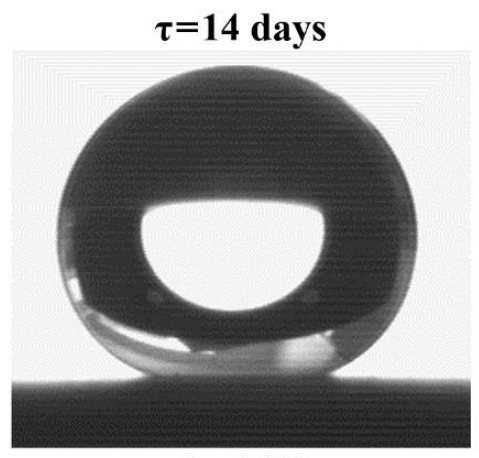

$\Theta=168^{\circ}$

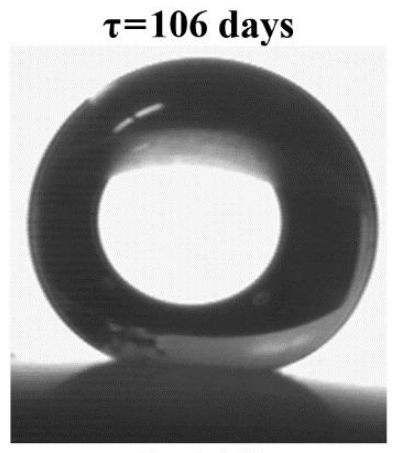

$\Theta=166^{\circ}$

Figure 5. Images of water droplets on the surface of a superhydrophobic coating at different times of exposure of the samples in an atmosphere with $\mathrm{NH}_{3}$ and $\mathrm{CO}_{2}$ under $100 \%$ humidity conditions. 


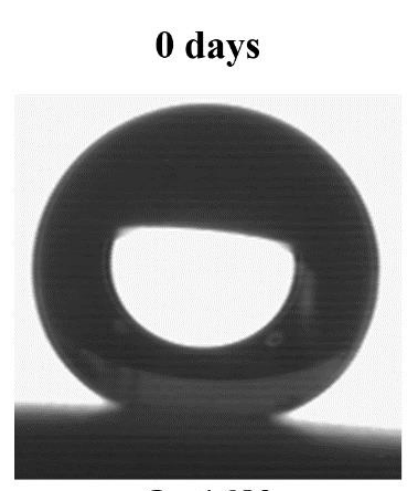

$\Theta=168^{\circ}$

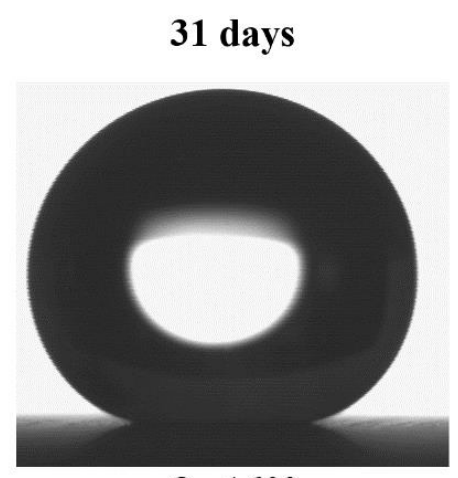

$\Theta=160^{\circ}$

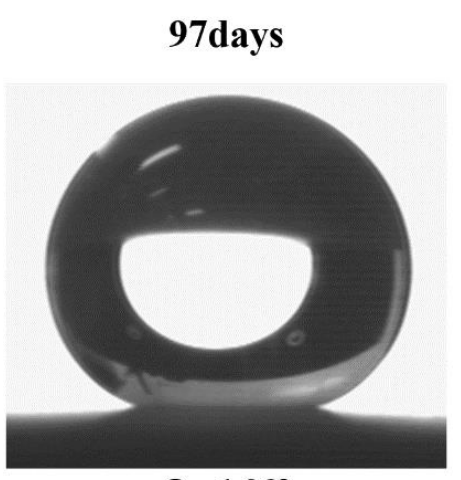

$\Theta=166^{\circ}$

Figure 6. Images of water droplets on the surface of a superhydrophobic coating at different times of exposure of the samples in an atmosphere with $\mathrm{NH}_{3}$ and $\mathrm{H}_{2} \mathrm{~S}$ under $100 \%$ humidity conditions.

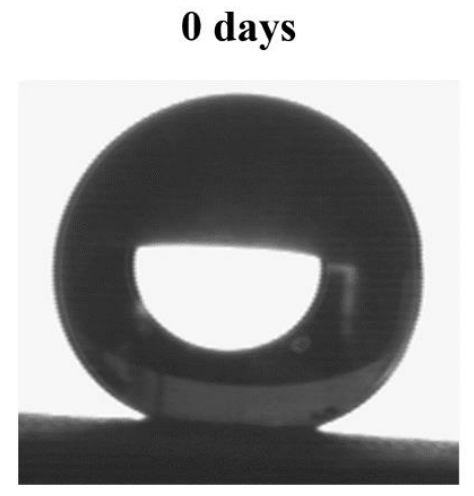

$\Theta=168^{\circ}$

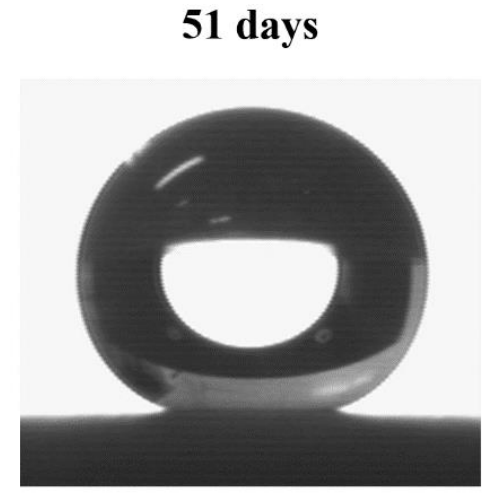

$\Theta=167^{\circ}$
97 days

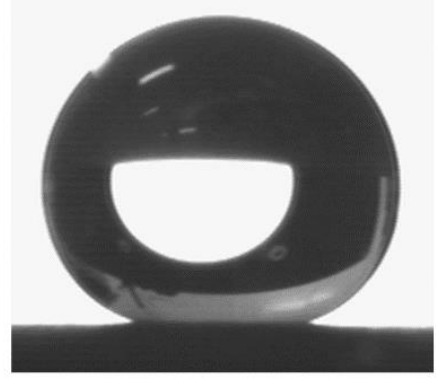

$\Theta=167^{\circ}$

Figure 7. Images of water droplets on the surface of a superhydrophobic coating at different times of exposure of the samples in an atmosphere with $\mathrm{CO}_{2}+\mathrm{NH}_{3}+\mathrm{H}_{2} \mathrm{~S}$ under $100 \%$ humidity conditions.

Under conditions of $100 \%$ humidity, a moisture film forms on the surface of the samples, in which the gases present in the atmosphere dissolve and hydrolyze. In this case, a solution of $\mathrm{H}_{2} \mathrm{~S}$ and $\mathrm{H}_{2} \mathrm{CO}_{3}$ is formed in an atmosphere with $\mathrm{CO}_{2}+\mathrm{H}_{2} \mathrm{~S}$. In an atmosphere with $\mathrm{NH}_{3}+\mathrm{H}_{2} \mathrm{~S}$, the resulting solutions of $\mathrm{NH}_{4} \mathrm{OH}$ and $\mathrm{H}_{2} \mathrm{~S}$ upon interaction should form the salt $\left(\mathrm{NH}_{4}\right)_{2} \mathrm{~S}$, which is almost completely hydrolyzed due to the fact that it is formed by a weak base and a weak acid, with the appearance of the starting compounds. Similarly, in an atmosphere with $\mathrm{NH}_{3}+\mathrm{CO}_{2}, \mathrm{NH}_{4} \mathrm{OH}$ and $\mathrm{H}_{2} \mathrm{CO}_{3}$ are present in the moisture film. In an atmosphere with $\mathrm{CO}_{2}+\mathrm{H}_{2} \mathrm{~S}+\mathrm{NH}_{3},\left(\mathrm{NH}_{4}\right)_{2} \mathrm{~S}$ and $\left(\mathrm{NH}_{4}\right)_{2} \mathrm{CO}_{3}$ are formed, which are also completely hydrolyzed to form two weak acids and a weak base.

The initial decrease in the contact angle in media containing $\mathrm{H}_{2} \mathrm{~S}$ is apparently associated with the activating effect of hydrogen sulfide in the pores of the coating (wetted areas on the superhydrophobic surface, the proportion of which can reach $10 \%$ [8]), but later the formation of poorly soluble iron sulfide occurs, partially healing defects. The contact angles that persist after 100 days of exposure, exceeding $160^{\circ}$, indicate a good protective 
effectiveness of the investigated superhydrophobic coatings in the presence of corrosion stimulants in maximum permissible concentrations. This is consistent with the data obtained on the basis of polarization measurements on the electrodes with a superhydrophobic coating in $\mathrm{NaCl}$ solutions with $\left(\mathrm{NH}_{4}\right)_{2} \mathrm{~S}$ or $\left(\mathrm{NH}_{4}\right)_{2} \mathrm{CO}_{3}$ additives [12].

In an atmosphere with $\mathrm{CO}_{2}+\mathrm{NH}_{3}$, the smallest decrease in the contact angle value over time is observed, and it is monotonous. By day 100, it has a value of about $167^{\circ}$ (Figure 4). This is apparently due to the minimal activating effect of $\mathrm{NH}_{4} \mathrm{OH}$ and $\mathrm{H}_{2} \mathrm{CO}_{3}$ with respect to the coating.

Weighing the electrodes with a superhydrophobic coating before and after exposure under appropriate conditions showed that there are no corrosion losses, on the contrary, an insignificant weight gain is observed. In the atmosphere with $\mathrm{CO}_{2}+\mathrm{H}_{2} \mathrm{~S}$, in the first 14 days, the weight gain of the coated samples is observed by $0.0005-0.0006 \mathrm{~g}$, after 106 days - by $0.0053-0.0054 \mathrm{~g}$ due to the formation of insoluble sulfide products. After washing and drying the surface, the contact angle was at least $160^{\circ}$. In an environment with $\mathrm{CO}_{2}+\mathrm{NH}_{3}$, the picture with the weight gain is similar. In the presence of $\mathrm{NH}_{3}+\mathrm{H}_{2} \mathrm{~S}$, the weight gain of the samples is practically absent during the entire test period; in the presence of all three stimulants, the weight gain of the samples is not more than $0.0001 \mathrm{~g}$ during the entire period.

\section{Conclusion}

A superhydrophobic coating formed on the surface of St3 steel samples based on a fluorooxysilane and characterized by a contact angle of about $172.6 \pm 1.2^{\circ}$ fully protects the metal against corrosion for 100 days in an atmosphere with $100 \%$ humidity and the presence of $\mathrm{CO}_{2}, \mathrm{H}_{2} \mathrm{~S}$ and $\mathrm{NH}_{3}$ corrosion stimulants in pairs and simultaneously all three in maximum permissible concentrations.

At the same time, the contact angle of wetting with water remains in the range of $167-162^{\circ}$, depending on the type of stimulants present.

Steel samples unprotected by the coating underwent intense corrosion under the investigated conditions.

\section{Acknowledgments}

This work was supported by the Ministry of Science and Higher Education of the Russian Federation in the framework of agreement No. 075-15-2021-709 (unique project identifier RF-2296.61321X0037).

\section{References}

1. L.B. Boinovich and A.M. Emel'yanenko, Hydrophobic materials and coatings: principles of creation, properties, application, Russ. Chem. Rev., 2008, 77, no. 7, $583-$ 600. doi: 10.1070/RC2008v077n07ABEH003775

2. J.T. Simpson, S.R. Hunter and T. Aytug, Superhydrophobic materials and coatings: a review, Rep. Prog. Phys., 2015, 78, 086501. doi: 10.1088/0034-4885/78/8/086501 
3. E. Vazirinasab, R. Jafari and G. Momen. Application of superhydrophobic coatings as a corrosion barrier: A review, Surf. Coat. Technol., 2018, 341, 40-56. doi: 10.1016/j.surfcoat.2017.11.053

4. V.I. Vigdorovich, L.E. Tsygankova, E.Yu. Shel, A.A. Uryadnikov and E.A. Skrypnikova, Superhydrophobization of metal surfaces and ways of its some practical use, Korroz.: Mater., Zashch. (Corrosion: materials, protection), 2017, no. 7, $1-13$ (in Russian).

5. Y. Wang, W. Wang, L. Zhong, J. Wang, Q. Jiang and X. Guo, Super-hydrophobic surface on pure magnesium substrate by wet chemical method, Appl. Surf. Sci., 2010, 256, no. 12, 3837-3840. doi: 10.1016/j.apsusc.2010.01.037

6. Z. Kang, Q. Ye, J. Sang and Y. Li, Fabrication of super-hydrophobic surface on copper surface by polymer plating, J. Mater. Process. Technol., 2009, 209, no. 9, 4543-4547. doi: $10.1016 /$ j.jmatprotec.2008.10.031

7. L.B. Boinovich, K.A. Emelyanenko, A.G. Domantovsky and A.M. Emelyanenko, Laser tailoring the surface chemistry and morphology for wear, scale and corrosion resistant superhydrophobic coatings, Langmuir, 2018, 34, no. 24, 7059-7066. doi: 10.1021/acs.langmuir.8b01317

8. D.A. Alpysbaeva, D.B. Vershok, A.M. Emel'yanenko, O.V. Batishchev, Yu.I. Kuznetsov and L.B. Boinovich, Superhydrophobization of low-carbon steel by surface coatings, Korroz.: Mater., Zashch. (Corrosion: materials, protection), 2013, no. 8, 42-47 (in Russian).

9. A.M. Semiletov, A.A. Chirkunov and Yu.I. Kuznetsov, Protection of aluminum alloy AD31 from corrosion by adsorption layers of trialkoxysilanes and stearic acid, Mater. Corros., 2020, 71, no. 1, 77-85. doi: 10.1002/maco.201911000

10. V.I. Vigdorovich, L.E. Tsygankova, M.N. Uryadnikova, K.A. Emel'yanenko, E.V. Chulkova, and A.A. Uryadnikov, Protective effect of superhydrophobic coatings on carbon steel in different environments, Int. J. Corros. Scale Inhib., 2021, 10, no. 3, 1157-1167. doi: 10.17675/2305-6894-2021-10-3-19

11. V.I. Vigdorovich, L.E. Tsygankova, N.V. Shel, E.Yu. Shel, L.G. Knyazeva, A.V. Dorokhov and A.A. Uryadnikov, Modeling corrosive atmospheres for evaluating the effectiveness of volatile inhibitors, Zavodskaya laboratoriya. Diagnostika materialov (Factory laboratory. Diagnostics of materials), 2018, 83, no. 7, 42-46 (in Russian). doi: 10.26896/1028-6861-2018-84-7-42-46

12. V.I. Vigdorovich, L.E. Tsygankova, M.N. Uryadnikova, N.V. Shel, L.G. Knyazeva and O.V. Alyokhina, Electrochemical study of carbon steel protection with a superhydrophobic coating under conditions of $100 \%$ humidity and the presence of corrosion stimulants in the air, Theory and Practice of Corrosion Protection, 2020, 25, no. 3, 17-26 (in Russian). 